\title{
Germination and seedling development in Stratiotes aloides L.
}

\author{
A.J.P. Smolders*, C. den Hartog, J.G.M. Roelofs. \\ Department of Ecology, Research Groups of Environmental Biology and Aquatic Ecology, \\ University of Nijmegen, Toernooiveld 6525 ED Nijmegen, The Netherlands
}

Accepted 9 February 1995

\begin{abstract}
Stratiotes aloides $\mathrm{L}$. seeds need neither light, nor oxygen, nor vernalization to germinate but the germlings need light and oxygen for further development. Germination, however, is delayed strongly by the mechanical resistance of the seed coat. After liberation from the fruit seeds float probably because small gas bubbles are trapped between the hairs of the seed coats. The different stages of seedling development are described.
\end{abstract}

Keywords: Stratiotes aloides; Germination; Seedling development

\section{Introduction}

According to Cook and Urmi-König (1983) seed production in the water soldier (Stratiotes aloides L.) is known in parts of Germany and Poland, the Danube (Donau) countries and Russia. In these regions the species is regarded to be native because male and female plants often occur together in the same area. Generally, however, recent finds of S. aloides seeds are considered to be rare.

In the Netherlands, Smolders et al. (1993, 1994, 1995), found seeds in S. aloides stands in the surroundings of the village of Giethoorn (province of Overijssel). Seeds were only present in large numbers in mixed stands. In these stands up to 1800 seeds per 100 female plants were found. In stands that consisted exclusively of female plants some seeds could sometimes be found if the stands were located less than $1 \mathrm{~km}$ from a male or mixed stand.

Although seedset can be quite substantial, even in mixed $S$. aloides stands the recruitment of new plants from seeds seems to be limited, (Smolders et al., 1995). Apart from predation on seedlings by snails such as Planorbarius corneus (L.) and adverse conditions owing to

\footnotetext{
* Corresponding author.
} 
the accumulation of phytotoxins in the anaerobic sediment (Smolders et al., 1995) delayed germination (Cook and Urmi-König, 1983) is thought to play a role.

In this paper we report on experiments on the germination of seeds collected in a Dutch $S$. aloides stand. Furthermore, the development of seedlings is described and the possible role of seeds in the dispersal of the species is discussed.

\section{Materials and methods}

Fully ripe fruits were collected in September/October 1992 in a mixed S. aloides stand in the vicinity of the village of Giethoorn (province of Overijssel). In the laboratory seeds
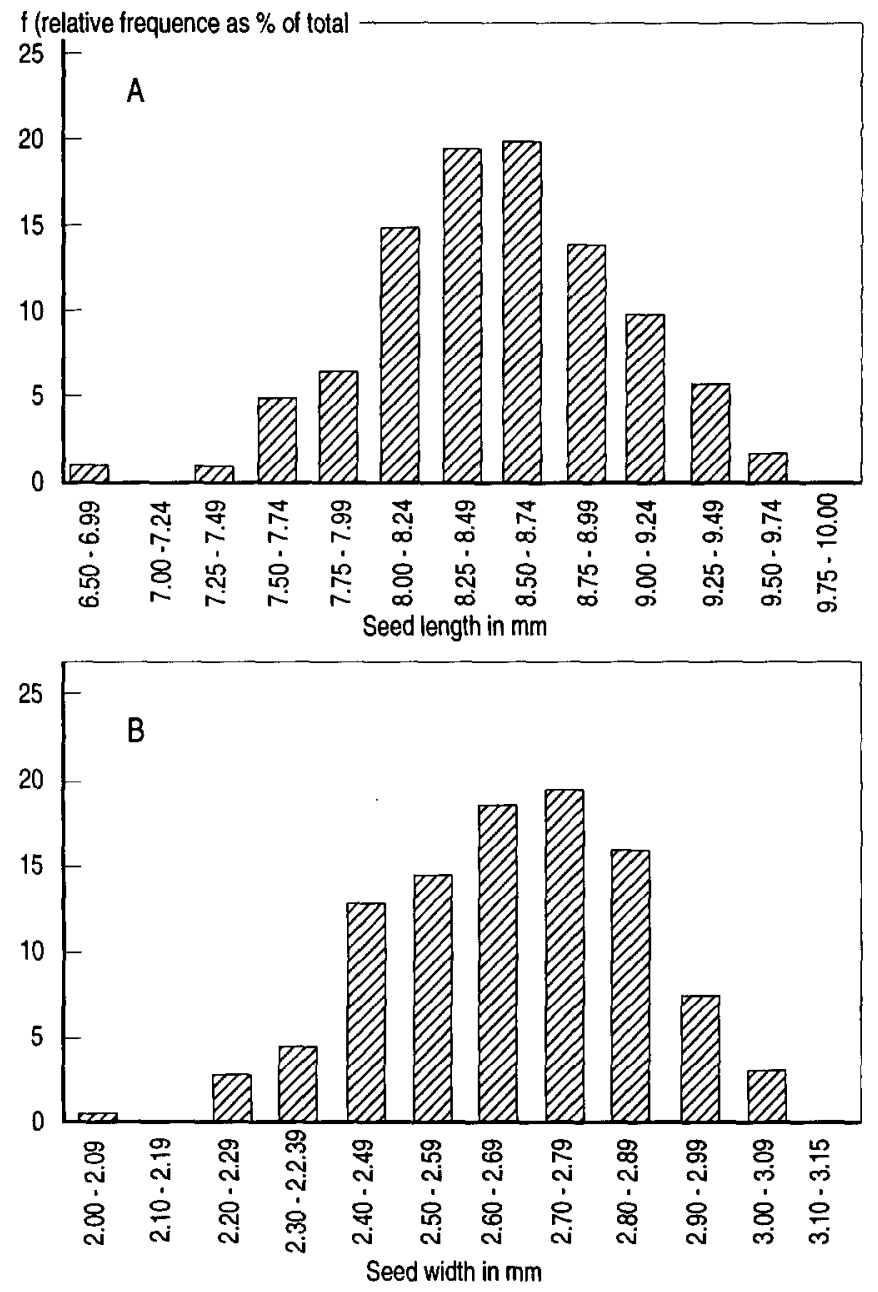

Fig. 1. Relative frequency (f) as percentage of total for seed length (A) and seed width (B) of seeds collected in a population of $S$. aloides near Giethoorn in the province of Overijssel (The Netherlands) in September 1992, $(n=250)$. 
were liberated from the fruits. For 250 seeds length and width were measured. Seeds were used for experiments as described below.

\subsection{Seed germination}

Freshly collected seeds of $S$. aloides were kept at $4^{\circ} \mathrm{C}$ in petri-dishes filled with fresh tap water. After being kept for different periods at $4^{\circ} \mathrm{C}$ seeds were incubated in an aerobic or a hypoxic medium, respectively in darkness or exposed to a photoperiod of $16 \mathrm{~h}$. Treatments were conducted in one or more batches of 25 seeds, in most cases after (careful) removal of the seed coat. In some experiments seeds were incubated together with the removed seed coats. Furthermore, experiments were conducted with seeds of which the seed coat was not removed but perforated; in this case many small holes ( \pm 0.5 in diameter) were carefully made with the aid of a needle in the seed coat.

Finally experiments were carried out with seeds with an intact seed coat after incubation at a temperature of $4^{\circ} \mathrm{C}$ for 3 months. Batches of 30 seeds were used and experiments were executed in triplicate.

In experiments under aerobic conditions seeds were incubated in open petri-dishes filled with fresh tap water. Hypoxic conditions were created by incubating the seeds in air-tight sealed glass bottles filled with tap water that was previously flushed with nitrogen gas (Smits et al., 1990).

All above described experiments were conducted at two different temperatures $\left(11^{\circ} \mathrm{C}\right.$ and $19^{\circ} \mathrm{C}$ ) in climate rooms, for a period of 4 weeks.

To check seed germination after passing animal digestive tracks the first author ate 25 seeds. The retrieved seeds were incubated in a petri dish at $19^{\circ} \mathrm{C}$ in the light. This experiment was carried out in duplo.

\subsection{Seedling development}

Freshly germinated seeds were incubated in a medium ( $\mathrm{pH} 6.8$ ) containing: $2000 \mu \mathrm{mol}$ $1^{-1}$ bicarbonate, $10 \mu \mathrm{mol}^{-1}$ ammonium, $10 \mu \mathrm{mol} \mathrm{l}^{-1}$ nitrate, $2000 \mu \mathrm{mol} \mathrm{l}^{-1}$ sodium,

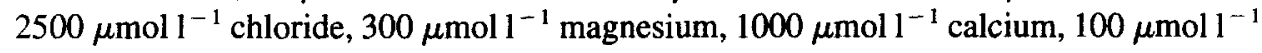

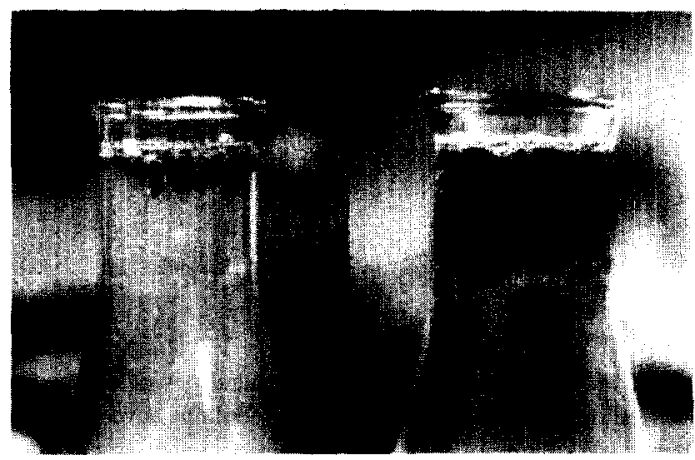

Fig. 2. Freshly shed seeds of S. aloides floating in top of an erlenmeyer. A. After 1 h of incubation $9 \%$ of the seeds were floating. B. After $5 \mathrm{~h}$ of incubation $96 \%$ of the seeds were floating. Total amount of incubated seeds was 100. 
sulphate, $100 \mu \mathrm{mol} \mathrm{l}^{-1}$ potasium and $0.5 \mu \mathrm{mol}^{-1}$ phosphate. Concentrations of the trace elements were the same as in Roelofs (1991). Photographs were made of different stages of development.

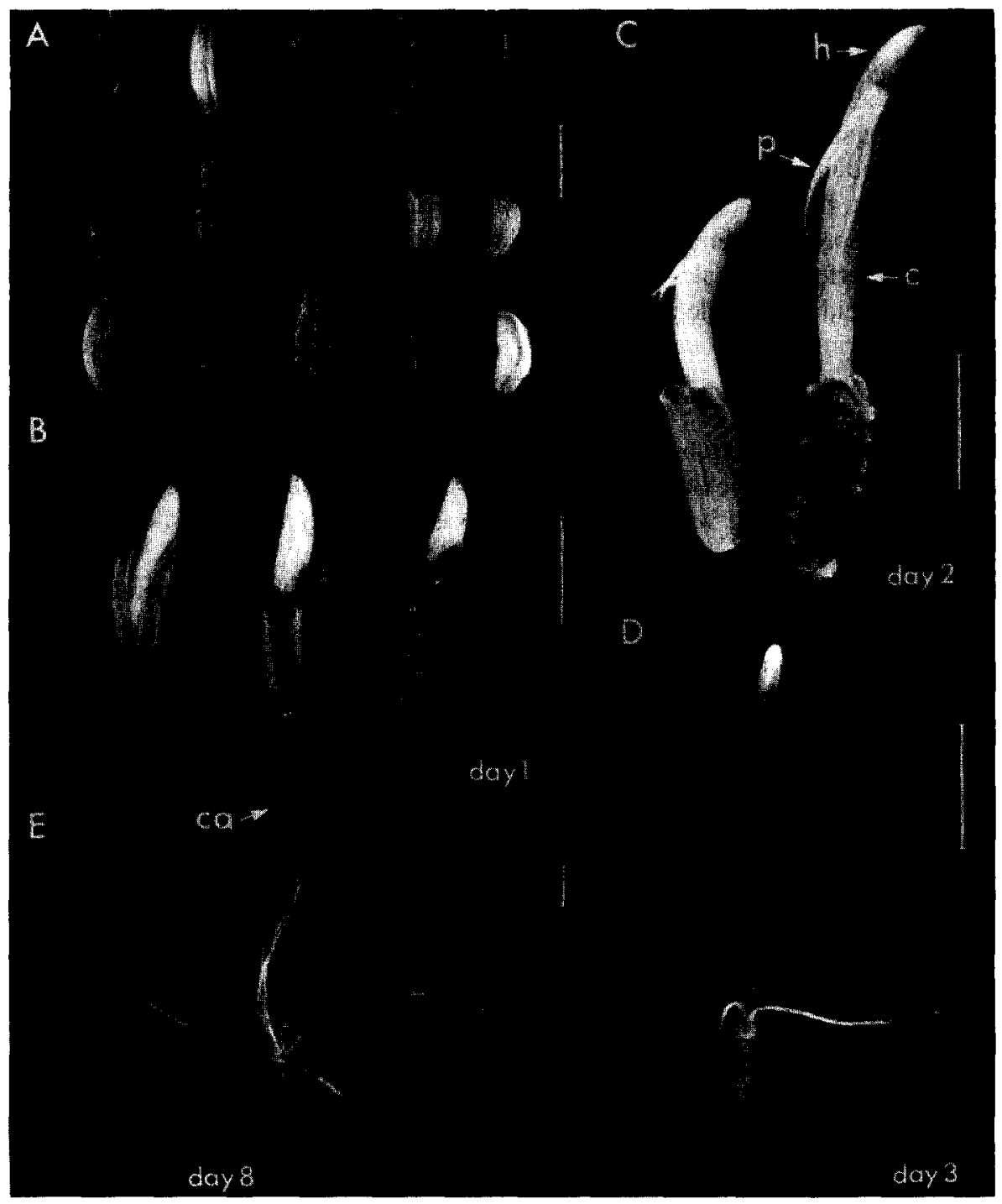

Fig. 3. A. Different seeds of $S$. aloides L. collected in the surroundings of Giethoorn. B. Different modes of germination in S. aloides. C. Seedlings 2 days after germination, seedlings have the seed coats still attached to the enlarging cotyledon ( $c ; h$, hypocotyl). Primordia of the first leaves ( $p$ ) are lying against the enlarging cotyledon. $D$. Seedling, 3 days after germination, the cotyledon is no longer attached to the seed coat while the primordia of the leaves are growing out and are no longer appressed to the cotyledon. E. Seedling, 8 days after germination. Leaves are growing out while the leaf apices are typically curled (ca). Bar indicates $5 \mathrm{~mm}$. 


\subsection{Buoyancy of seeds}

One hundred seeds collected from ripe fruits were incubated in an erlenmeyer containing the same medium as described under the previous heading. Photographs were taken $1 \mathrm{~h}$ and $5 \mathrm{~h}$ after incubation, respectively.

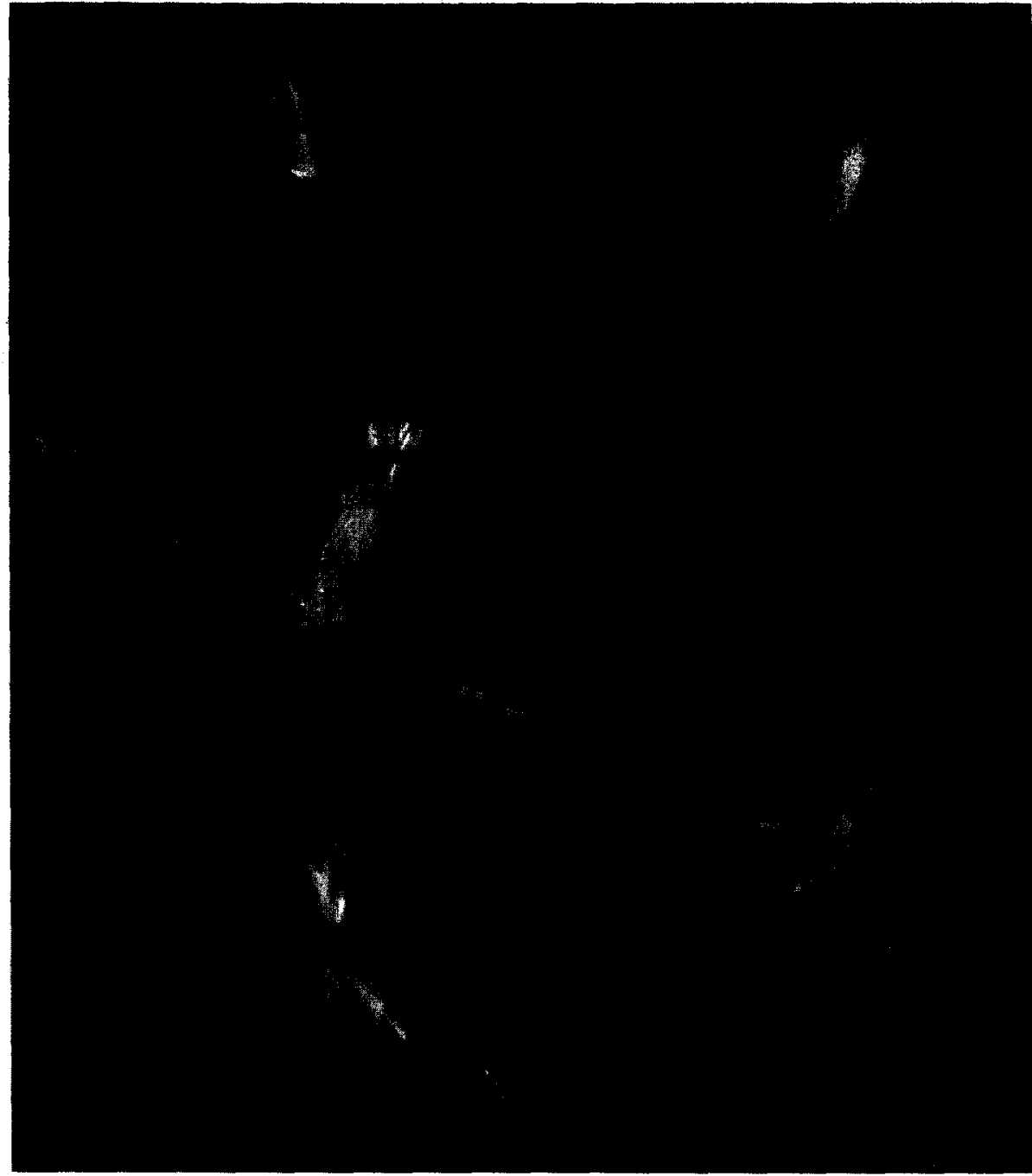

Fig. 4. A. Seedling, 20 days after germination, Some new leaves are produced, the leaf width is increasing and the first root ( $r$ ) appears at the base of the seedling. B. Detail of the first side root $(r)$ at the base of the seedling. C. Seedling, 30 days after germination. The root has only slightly increased in length and the cotyledon (c) is still present. D/E. Seedling, 60 days after germination. The seedling already shows the typical appearance of a Stratiotes plant. The cotyledon has disappeared and the first root $(r)$ has increased in length. One of the oldest leaves is already decaying. Bar indicates $5 \mathrm{~mm}$. 


\section{Results}

\subsection{Seed shape and seed size}

Fig. 3a shows some $S$. aloides seeds collected in the stand near Giethoorn. Seed shape, seed length and seed width appear to differ considerably. Fig. 1 shows that seed length and seed width are more or less normally distributed and vary between $6.50 \mathrm{~mm}$ and $9.75 \mathrm{~mm}$, and $2.00 \mathrm{~mm}$ and $3.10 \mathrm{~mm}$ respectively. The mean length and mean width amount to 8.50 $\mathrm{mm}$ and $2.61 \mathrm{~mm}$, respectively.

\subsection{Buoyancy of the seeds}

The seeds that were liberated after ripening of the fruits in the laboratory possessed the typical unicellular hairs that in accordance with the description of Cook and Urmi-König (1983) in most cases decayed within a few months. Within several hours after liberation and incubation in the erlenmeyer most of the seeds became floating while many gas-bubbles were observed between the seed hairs. Fig. 2 illustrates the floating ability of the seeds. After $1 \mathrm{~h} 9 \%$ of the seeds had become floating (Fig. 2a) whereas after $5 \mathrm{~h} 96 \%$ of the seeds were floating (Fig. 2b).

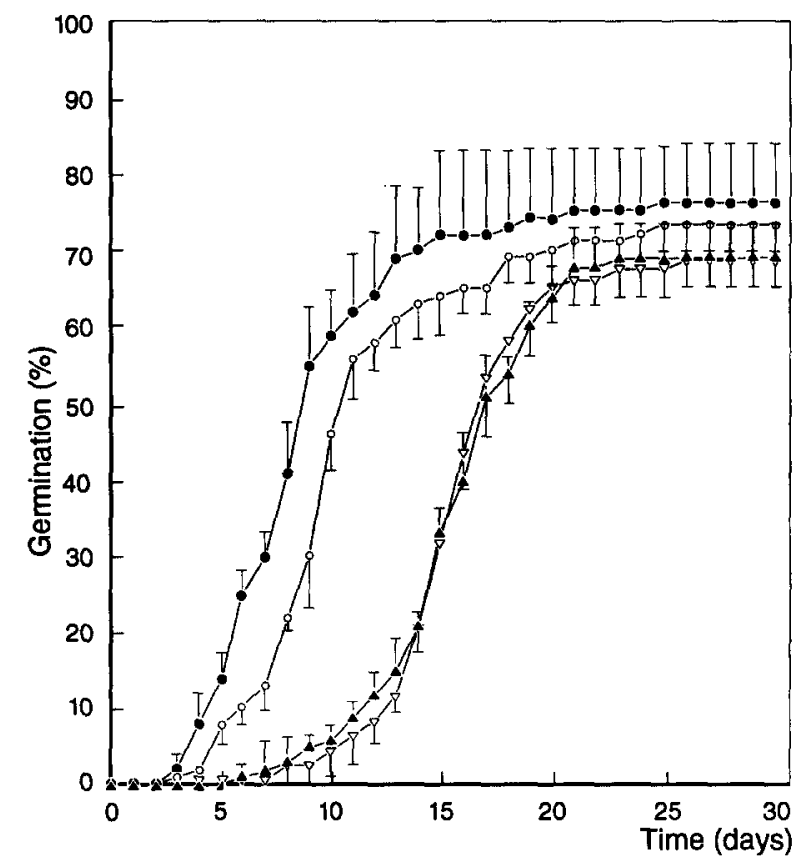

Fig. 5 Cumulative germination of $S$. aloides seeds after removal of the seed coat. $\bullet$, hypoxic at $19^{\circ} \mathrm{C}$ conditions; $\mathrm{O}$, aerobic at $19^{\circ} \mathrm{C} ; \boldsymbol{\Lambda}$, hypoxic at $11^{\circ} \mathrm{C}$ and $\nabla$, aerobic at $11^{\circ} \mathrm{C}$. 


\subsection{Modes of germination}

Three different modes of seed germination were observed (Fig. 3b). In some cases seed coats did split longitudinally over their total length (left), while in some other cases only the top of the seed coat tore open (middle). Mostly, however, part of the seed coat did split longitudinally (right).

\subsection{Seedling development}

Seedlings only developed under aerobic conditions with sufficient light. Under hypoxic conditions or in the dark all seedlings died within two weeks after germination.

Figs. 3 and 4 show some typical stages of the first 2 months of the development of the Stratiotes seedlings reared in the laboratory.

One day after germination, the enlarging cotyledon of the seedlings is still attached to the seed coat (Fig. 3c) while the primordia of the first leaves are lying against the cotyledon.

Three days after germination the cotyledon is usually detached from the seed coat while the primordia are growing out and are no longer appressed to the cotyledon (Fig $3 \mathrm{~d}$ ). In the next week leaves are growing out. Leaf apices are typically curled (Fig $3 \mathrm{e}$ ).

In the following weeks new leaves are produced, the leaf width increases and approximately 3 weeks after germination the first root appears at the base of the seedling. After 2

Table 1

Germination of Stratiotes aloides seeds under different conditions. Seeds without or with perforated seed coats were germinated in batches of 25 seeds at 11 or $19^{\circ} \mathrm{C}$ for a period of 4 weeks. $N$ between parentheses indicates the number of replicates. Seeds were collected in September 1992 in a location in the vicinity of Giethoorn

\begin{tabular}{|c|c|c|c|c|}
\hline & $19^{\circ} \mathrm{C}$ & & $11^{\circ} \mathrm{C}$ & \\
\hline \multicolumn{5}{|c|}{ Incubation in light after different cold periods $\left(4^{\circ} \mathrm{C}\right)$} \\
\hline 4 months (aerobic) & 18.25 & $(n=4)$ & 17 & $(n=4)$ ( see also Fig. 5$)$ \\
\hline 4 months (hypoxic) & 19 & $(n=4)$ & 17.25 & $(n=4)$ ( see also Fig. 5) \\
\hline 2 months (aerobic) & 18 & $(n=1)$ & 18 & $(n=1)$ \\
\hline 0 months (aerobic) & 19 & $(n=1)$ & 17 & $(n=1)$ \\
\hline \multicolumn{5}{|c|}{ Incubation in dark after cold period $\left(4^{\circ} \mathrm{C}\right)$ of 4 months } \\
\hline Aerobic & 18 & $(n=1)$ & 20 & $(n=1)$ \\
\hline Hypoxic & 18 & $(n=1)$ & 17 & $(n=1)$ \\
\hline \multicolumn{5}{|c|}{ With incubation of removed seed coats } \\
\hline Aerobic & 20 & $(n=1)$ & 17 & $(n=1)$ \\
\hline \multicolumn{5}{|c|}{ With perforated seed coats } \\
\hline Aerobic & 1 & $(n=1)$ & 0 & $(n=1)$ \\
\hline \multicolumn{5}{|l|}{ Intact seeds } \\
\hline Aerobic & 1 & $(n=4)$ & 0 & $(n=4)$ (see also Fig. 6) \\
\hline Hypoxic & 1 & $(n=4)$ & 0 & $(n=4)$ (see also Fig. 6) \\
\hline \multicolumn{5}{|c|}{ Intact seeds retrieved from faeces } \\
\hline Repl. 1 & 9 & & - & \\
\hline Repl. 2 & 7 & & - & \\
\hline
\end{tabular}



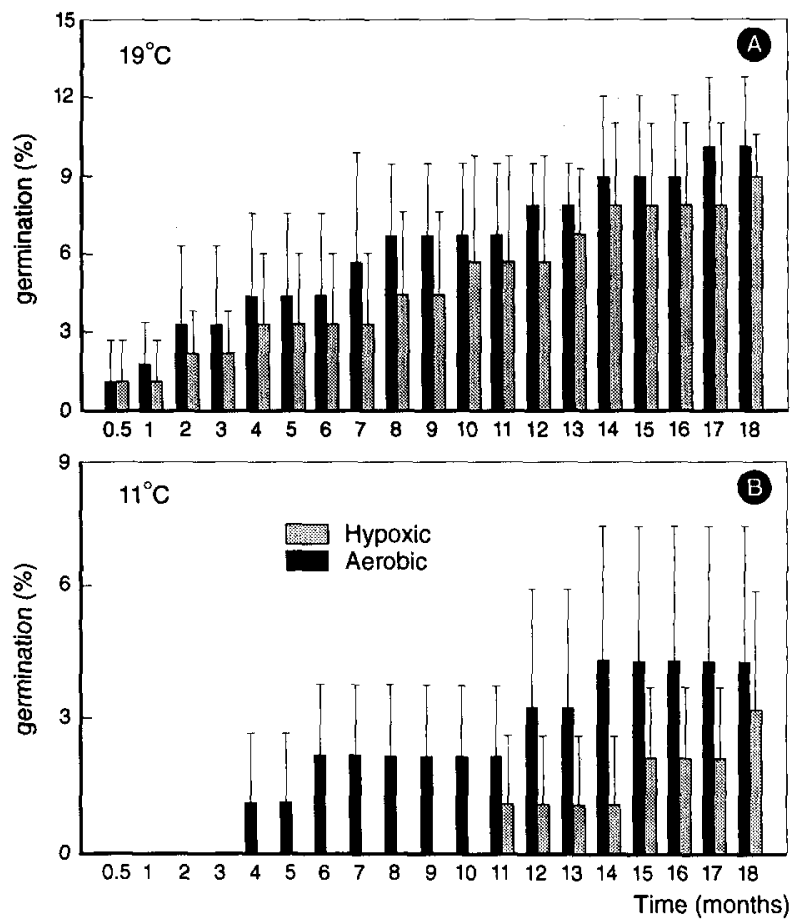

Fig. 6. Cumulative germination of intact S. aloides seeds. A. At $19^{\circ} \mathrm{C}$ under hypoxic and aerobic conditions. B. At $11^{\circ} \mathrm{C}$ under hypoxic and aerobic conditions.

months the seedlings already show the typical appearance of a Stratiotes plant and the cotyledon has disappeared (Fig. 4).

\subsection{Germination experiments}

Fig. 5 shows the cumulative germination after removal of the seed coat under aerobic and hypoxic conditions and at two different temperatures. Seeds were considered germinated when the cotyledon had increased in size more than one fifth of its length. In all cases seeds developed into young seedlings once the cotyledon had started to enlarge. At a temperature of $19^{\circ} \mathrm{C}$ germination starts 3 days after removal of the seed coat and most of the seeds germinate within 2 weeks after onset of the experiment. Under hypoxic conditions seeds germinate slightly better than under aerobic conditions. The differences, however, are only marginal. At a temperature of $11^{\circ} \mathrm{C}$, there is a clear delay in seed germination while no differences are observed between the aerobic and hypoxic treatments.

Table 1 shows the effects of different treatments on the number of seeds germinating within 30 days after onset of the experiments. The table shows that approximately $70 \%$ of the seeds germinate after removal of the seed coat. Furthermore temperature, light vs. dark, aerobic vs. hypoxic conditions, and incubation with or without the removed seed coats do not have much effect on the amount of seeds germinating within 30 days. Of the seeds with perforated seed coats, however, only one seed germinated within 30 days. 
All the seeds that were eaten were retrieved intact in the faeces within 2 days after consumption. In the two batches of 25 seeds respectively seven and nine seeds germinated within 30 days (Table 1 ).

Seeds with intact seed coats that had not previously passed a digestive track germinated very slowly. After 18 months only $9-10 \%$ of the seeds incubated at $19^{\circ} \mathrm{C}$ and $3-4.4 \%$ of the seeds incubated at $11^{\circ} \mathrm{C}$ had germinated (Fig. 6). Aerobic vs. hypoxic incubations did not reveal important differences although the aerobic incubated seeds germinated earlier.

\section{Discussion}

The only available earlier descriptions of seedling development are those of Klinsmann (1860) and Irmisch (1865). The observed development, described in this paper, is in accordance with these earlier descriptions.

The mean seed length and mean seed width of the 40 seeds collected in the University Botanical Garden of Zürich and studied by Cook and Urmi-König (1983) amounted to $9.02 \pm 0.87 \mathrm{~mm}$ and $2.66 \pm 0.21 \mathrm{~mm}$, respectively. For the seeds that we collected in the Giethoorn population $(n=250)$, the mean seed length $(8.50 \mathrm{~mm})$ was somewhat smaller while the mean seed width was more or less the same $(2.61 \mathrm{~mm})$. The dormancy of the seeds appears to be controlled mainly by the seed coat (coat-imposed dormancy; Bewley and Black, 1982). As soon as the seed coat is removed as much as $70 \%$ of the seeds germinate readily without requiring light, oxygen or vernalization. These observations are in accordance with observations of Cook and Urmi-König (1983). As perforation of the seed coat did not enhance seed germination it does not seem likely that dormancy is the result of an interference with water uptake of the seed coat. As the seed coat is thick and tough, mechanical resistance of the seed coat could play an important role. Mechanical resistance of the seed coat is also known to delay germination of other aquatic macrophytes such as Alisma plantago-aquatica L. and some Sagittaria and Eichhornia species (Crocker and Davis, 1914). Although co-incubation of seeds and seed coats did not prevent germination, the observation that germination did not start immediately but, with or without the co-incubation of seed coats, only a few days after removal of the seed coat (Fig. 5) could indicate that inhibiting substances (produced) in the seed coat are also involved.

Delayed germination is a strategy that seems to fit well in the life cycle of a species with extensive clonal growth such as $S$. aloides. However, Stratiotes stands build up a thick sapropel layer and, therefore, seeds are bound to be covered with an anoxic sapropel layer within a few years. Seeds of several aquatic species are well known to survive for a (very) long time in sediments. The Stratiotes seeds are able to germinate in the dark and under hypoxic conditions. Under hypoxic conditions or in the dark, however, seedlings do not develop very well and die within a few weeks after germination. Therefore, seeds that do not germinate within a few years after seedset and are covered with a thick anaerobic sapropel layer are unlikely to contribute to recruitment unless the bottom is disturbed.

Although many attempts have been made in autumn as well as in spring to find seedlings in the natural environment only one seedling of $S$. aloides has been found in the spring of 1993 within a Stratiotes stand. All the other small plantlets found had developed from 
turions as could be easily established from the presence of a scar at the place were the turion had been connected to the stolon.

Cook and Urmi-König (1983) wonder why the seeds of S. aloides possess the typical unicellular hairs. It is suggested that these hairs play a role in seed dispersal. Stratiotes is known to prefer $\mathrm{CO}_{2}$-rich waters (high alkalinity and moderate $\mathrm{pH}$ ) (Prins and de Guia, 1986). Furthermore, Stratiotes normally occurs on highly reduced sediments (De Lyon and Roelofs, 1988) in which the production of gases such as methane and $\mathrm{CO}_{2}$ can be substantial. Under these conditions small gas-bubbles become trapped between the hairs of the seeds and the seeds consequently become floating.

Buoyancy will facilitate hydrochoric dispersal of the seeds. After they are liberated from the fruits in autumn, when the Stratiotes plants are sinking or have already sunk to the bottom, seeds are easily dispersed by autumn winds. This may especially account for those stands that border on vaste water bodies. Outside the Stratiotes stands chances of seedlings to develop, even after a period of a few years, are generally better because there will be less sapropel accumulation.

The many records of fossil Stratiotes seeds in coprolites (Cook and Urmi-König, 1983) indicate that seeds may be dispersed by animals (endozoochoric dispersion). Seeds liberated but covered by overwintering prickly Stratiotes plants are not likely to be eaten. The buoyancy of the seeds, however, increases the chance that seeds are eaten by waterfowl, fish or other animals. For some aquatic species it is known that seed germination is enhanced after passing the digestive system of birds or carps by weakening the seed coat and/or by suppressing the action of chemical inhibitors produced by the seed coat (Lohammer, 1954; Smits et al., 1989). As seed germination is enhanced after passing the digestive track of an human being it is not unlikely that seeds are not only dispersed by animals but that germination of Stratiotes is also enhanced following endozoochoric dispersal.

In conclusion it is proposed that protracted germination in combination with the floating ability of the seeds seems to be functional because chances of (endozoochoric and hydrochoric) dispersal, germination and establishment of $S$. aloides on new locations are increased. In the surroundings of Giethoorn many of the Stratiotes stands are mixed and produce ample amounts of seeds (Smolders et al., 1995). In this area S. aloides is abundant in many ditches which points to an efficient dispersal of the species. Dispersal is probably the most important function of seeds of species with an extensive vegetative propagation, especially when the recruitment of seedlings is very low as seems to be the case for $S$. aloides (Smolders et al., 1995).

\section{Acknowledgement}

The authors thank A.H.N. van Duynhoven for practical assistance and H. Spruyt for photographing seeds and seedlings.

\section{References}

Bewley, J.D. and Black, M., 1982. Physiology and Biochemistry of Seeds (in Relation to Germination). Part 2 Viability, Dormancy and Environmental Control. Springer, Berlin, 375 pp. 
Cook, C.D.K. and Urmi-König, K., 1983. A revision of the genus Stratiotes (Hydrocharitaceae). Aquat. Bot., 16: 213-249.

Crocker, W. and Davis, W.E., 1914. Delayed germination in seed of Alisma plantago. Bot. Gaz., 58: 285-321.

Irmisch, T., 1865. Beitrag zur Naturgeschichte des Stratiotes aloides. Flora, N.F., 23: 81-91.

Klinsmann, F., 1860. Ein Beitrag zur Entwickelungsgeschichte von Stratiotes aloides. Bot. Zeitung, 18: 81-82.

Lohammer, G., 1954. The effect of digestion on the germination of Potamogeton seeds. Fauna och Fauna, Häfter, 1-2: $17-32$.

Prins, H.B.A. and de Guia, M.B., 1986. Carbon source of the water soldier (Stratiotes aloides L.). Aquat. Bot., 26: $225-234$.

Roelofs, J.G.M., 1991. Inlet of alkaline river water into peaty lowlands: Effects on water quality and Stratiotes aloides L. stands. Aquat. Bot., 39: 267-293.

Smits, A.J.M., van Ruremonde, R. and van der Velde, G., 1989. Seed dispersal of three Nymphaeid macrophytes. Aquat. Bot., 35: 167-180.

Smits, A.J.M., van Avesaath, P.H. and van der Velde, G., 1990. Germination requirements and seed banks of some Nymphaeid macrophytes: Nymphaea alba L., Nuphar lutea (L.) Sm. and Nymphoides peltata (Gmel.) O. Kuntze. Freshwater Biol., 24: 315-326.

Smolders, A., van Duynhoven, A.H.N. and Roelofs, J.G.M., 1993. Vruchtzetting en zaadproductie van Krabbescheer (Stratiotes aloides L.) in Nederland. Gorteria, 19: 55-61.

Smolders, A., van Duynhoven, A.H.N. and Roelofs, J.G.M., 1994. Frucht- und Samenansatz der Krebsschere (Stratiotes aloides L) in den Niederlande. Aqua Planta, 19: 11-19.

Smolders, A., den Hartog, C. and Roelofs, J.G.M., 1995. Observations on fruiting and seed-set of Stratiotes aloides L. in the Netherlands. Aquat. Bot., 51: 259-268. 